\title{
Entre o oficial e o realizado: os currículos prescritos e em ação na Matemática do Ciclo de Alfabetização
}

\author{
Entre el oficial y lo realizado: los currículos prescritos y en acción en la
}

Matemática del Ciclo de Alfabetización

Between the official and the accomplished: the core prescribed and the core in action in the Mathematics of the Elementary School

\author{
Fabrício Monte Freitas ${ }^{1}$ \\ João Alberto da Silva ${ }^{2}$ \\ Crislaine de Anunciação Roveda ${ }^{3}$ \\ Paola Reyer Marques ${ }^{4}$
}

\begin{abstract}
Resumo
O trabalho busca compreender como se dá a relação entre as três "engrenagens" básicas - currículos proposto, em ação e avaliado - para o desenvolvimento da educação brasileira, levando em conta as traduções que são realizadas pelos professores dos discursos pedagógicos oficiais até o campo recontextualizado pedagógico, que é o que de fato acontece na sala de aula. $\mathrm{O}$ trabalho pretende analisar as matrizes de referência das avaliações externas, bem como os três livros didáticos de matemática mais utilizados no Ciclo de Alfabetização. Essa análise, juntamente com o discurso apresentado pelas professoras em entrevistas semiestruturadas, constituirá o corpus de análise do estudo a ser desenvolvido. Para isso, serão utilizados caminhos qualitatitavos, em uma abordagem descritiva e documental. As entrevistas semiestruturadas realizadas com as professoras serão analisadas por meio da analise de conteúdo. O esperado é que, a partir dessa pesquisa, seja possível observar se as professoras do Ciclo de Alfabetização compreendem as relações que estão presentes entre os currículos proposto e avaliado, em larga escala pelo Governo Federal, e o em ação, realizado na sala de aula em Matemática no Ciclo de Alfabetização.
\end{abstract}

Palavras-Chave: Anos Iniciais, Ciclo de Alfabetização, Currículo, Discurso Pedagógico, Matemática.

\section{Resumen}

El trabajo busca comprender cómo se da la relación entre los tres "engranajes" básicos - currículos propuesto, en acción y evaluado - para el desarrollo de la educación brasileña, teniendo en cuenta las traducciones que son realizadas por los profesores de los discursos pedagógicos oficiales hasta el campo recontextualizado pedagógico, que es lo que efectivamente acontece en la clase. El trabajo pretende analizar las matrices de referencia de las evaluaciones externas, así como los tres libros didácticos de matemáticas más utilizados en el Ciclo de Alfabetización. Este análisis, junto con el discurso presentado por las profesoras en entrevistas semiestructuradas, constituirán el corpus de análisis del estudio a ser desarrollado. Para ello, se utilizarán

\footnotetext{
${ }^{1}$ Doutorando em Educação em Ciências: Química da Vida e Saúde; Universidade Federal de Rio Grande; Rio Grande, Rio Grande do Sul, Brasil; fmfreitas86@hotmail.com.

${ }^{2}$ Doutor em Educação; Universidade Federal de Rio Grande; Rio Grande, Rio Grande do Sul, Brasil; joaosilva@furg.br .

${ }^{3}$ Mestranda em Educação em Ciências: Química da Vida e Saúde; Universidade Federal de Rio Grande; Rio Grande, Rio Grande do Sul, Brasil; crislaine@furg.br.

${ }^{4}$ Doutoranda em Educação em Ciências: Química da Vida e Saúde; Universidade Federal de Rio Grande; Rio Grande, Rio Grande do Sul, Brasil; paolareyer@gmail.com.
} 
caminos cualitativos, en un enfoque descriptivo y documental. Las entrevistas semiestructuradas realizadas con las profesoras serán analizadas por medio del análisis de contenido. Lo esperado es que, a partir de esa investigación, sea posible observar si las profesoras del Ciclo de Alfabetización comprenden las relaciones que están presentes entre los currículos propuesto y evaluado, en gran escala por el Gobierno Federal, y el currículo en acción, realizado en las clases de Matemática en el Ciclo de Alfabetización.

Palabras Clave: Años iniciales, Ciclo de Alfabetización, Currículo, Discurso Pedagógico, Matemática.

\begin{abstract}
This work wants to understand how the relationship between the three basic "gears" - cure proposed, core in action and core evaluated - for the development of brazilian education. The support is the translations that are carried out by the teachers of the official pedagogical discourses to the recontextualized field pedagogical. The paper intends to analyze the reference matrices of the external assessements and the three mathematical textbooks most used in the Literacy Cycle. This analysis included the discourse presented by the teachers in semistructured interviews constitute the corpus of analysis of the study to be developedThe metodologichal is qualitative in a descriptive and documentary approach. The semistructured interviews with the teachers will be analyzed through content analysis. It is expected that, from this research, it will be possible to observe if the teachers of the Literacy Cycle understand the relationships that are present between the core proposed and evaluated, in large scale by the Brazilian Federal Government and the in action, carried out in the classroom in Mathematics in the Literacy Cycle.
\end{abstract}

Keywords: Elementary School, Literacy Cycle, Core, Pedagogical Speech, Mathematics.

\title{
1. Introdução
}

A necessidade de compreender como se dá a relação entre o que as políticas públicas avaliam nas escolas e nos estudantes através das Avaliações Externas, tal como a Provinha Brasil de Matemática - PBM e a Avaliação Nacional de Alfabetização -ANA, bem como o que é emitido pelo Governo como material didático, tais como os livros didáticos que são autorizados a estarem nas escolas depois de passarem por avaliação do Programa Nacional do Livro Didático - PNLD, além das práticas que são realizadas pelos professores em sala de aula.

Não há grande discussão acerca do assunto. No Banco de Teses e Dissertações - BTD, da Coordenação de Aperfeiçoamento de Pessoal de Nível Superior (CAPES), foram encontrados cinco trabalhos (Caldatto, 2015; Teixeira, 2007; Lima, 2014; Palanch, 2016; Martins, 2016) que tratavam sobre currículo proposto e currículo avaliado, sendo que, destes, apenas um falava especificamente sobre o comparativo entre o quê se avalia e o quê se tem em materiais didáticos, porém a discussão estava vinculada a um curso de pós graduação.

Pensamos, então, que um tema que precisa ser discutido, devido aos baixos índices obtidos pelas escolas nas avaliações externas, é a questão do currículo avaliado e do currículo proposto. Ou seja, o currículo que está sendo proposto pelo Governo Federal com a indicação de determinados livros didáticos através do PNLD e a sua relação com o currículo avaliado, também, pelo Governo Federal através das avaliações externas. 


\section{Currículo}

O currículo pode ser entendido de diversas formas sobre inúmeras teorias. É fundamental perceber que quando estruturamos um currículo estamos selecionando o tipo de pessoas que queremos formar. Para Silva (2015), para cada modelo de pessoas que queremos "moldar" necessitaremos de um conhecimento diferente e, por sua vez, um currículo diferente. Dessa forma, existem diversas teorias curriculares, desde as mais tradicionais até as pós-críticas.

Bernstein (1996) sugere que temos diferentes discursos pedagógicos que norteiam os currículos que são elaborados até os currículos que chegam ao aluno. Porém, durante esse caminho, os currículos sofrem adaptações e releituras que fazem com que esse discurso pedagógico também acaba por ser alterado. Ainda para o autor (idem), as pessoas que elaboram os currículos em esferas governamentais possuem um discurso pedagógico oficial e são construídos de forma estruturada e encaixada. Após esse primeiro momento, esse discurso pedagógico oficial chega ao PNLD e aos cursos de formação continuada oferecidos pelo Ministério da Educação - MEC. Aqui, ainda temos um mesmo discurso que é estruturado por especialistas indicados pelo Governo. Esse discurso pedagógico oficial é o que será cobrado, posteriormente, nas avaliações externas.

Esse discurso, ao chegar à escola, sofre uma primeira reelaboração, que Bernstein (1996) chama de tradução, que acontece com a construção do Projeto Político Pedagógico da escola, bem como dos planos de estudo elaborados pelos professores. Contudo, quando chega na sala de aula, o discurso pedagógico oficial, depois de transformado pela escola, é, novamente, traduzido pelo professor para sua prática cotidiana. Esse "novo" discurso se distancia do discurso pedagógico oficial por considerar todas as dificuldades da sala de aula, de aprendizagem dos alunos, da falta de recursos das escolas (sejam materiais ou de pessoal), entre outras adversidades que ocorrem nas escolas e na sala de aula.

No mesmo sentido, Sacristán (1998) sugere que existem diversos tipos de currículo que precisam ser levados em conta: (a) currículo prescrito ou regulamentado, que é o discutido e elaborado no âmbito das decisões políticas e administrativas do Estado; (b) currículo proposto ou planejado, que explicaremos a seguir seu conteúdo; (c) currículo organizado, estabelecido pela escola em seus documentos oficiais - Projeto Político Pedagógico, Planos de Ensino; (d) currículo em ação, que é o quê, de fato, acontece na sala de aula e chega aos alunos; e, (e) currículo avaliado, podendo este ser interna ou externamente. Para o autor o currículo proposto (ou planejado) é aquele currículo que vem descrito nos materiais didáticos, tais como livros, apostilas, guias, etc. e é elaborado para ser consumido 
por professores e alunos. No caso do Brasil, esses materiais (livros didáticos) são elaborados por editoras e submetidos à avaliação do Ministério da Educação - MEC. Logo, quando um livro está conforme as regras estipuladas pelo Governo, ele recebe um carimbo do PNLD e passa a integrar um catálogo que é distribuído as escolas. Dentre as diversas possibilidades de livros, as escolas, em conjunto com os professores, escolhem o quê acreditam ser o melhor para trabalhar com seus alunos. Assim, feita a escolha, os livros são enviados - conforme disponibilidade - às escolas. O currículo em ação é o que, de fato, acontece na sala de aula. É o currículo que os professores planejam e executam independentemente dos documentos oficiais.

Ainda de acordo com Sacristán (idem), o currículo avaliado é tratado como política pública de controle. As avaliações que são aplicadas no quinto e nono ano do Ensino Fundamental, juntamente com a aplicada no Ensino Médio, servem como componente para os resultados do Índice de Desenvolvimento da Educação Básica - IDEB. A PBM que é aplicada no segundo ano do Ensino Fundamental, não é considerada no IDEB, porém serve como parâmetro para as escolas perceberem o desenvolvimento que seus alunos tiveram durante aquele ano letivo já que sua aplicação ocorre no início e ao final do ano letivo.

\section{Avaliação}

A avalição educacional, de acordo com Roldão (2015), é parte constituinte do desenvolvimento curricular, sendo o fim dos processos de ensino e de aprendizagem e responsável pela aferição e regulação das aprendizagens construídaspelos estudantes. É importante compreender que a dimensão adotada desde o século XIX através da organização tradicional e mecanicista em que a educação é estruturada separa os espaços de avaliação e do currículo, fazendo deles, dois campos de conhecimentos distintos. Esses conceitos foram sendo transmitidos e perdendo sua originalidade.

De acordo com Wiebusch (2011), a avaliação educacional passou a ser entendida através de suas duas dimensões: (1) uma interna, realizada pelo professor, parte constituinte do processo, e outra, (2) externa, que é realizada por algum ente externo à escola - geralmente concretizada em grande escala pelo gestor educacional, seja ele em nível Municipal, Estadual ou Federal. Desse modo, não podemos considerar essas duas avaliações sinônimas, pois são duas modalidades que se diferenciam pela intencionalidade e objetivos: a segunda, realizada em grande escala, verifica os desempenhos dos estudantes em determinados campos de conhecimento, não expressando o conjunto das aprendizagens realizadas na escola, apenas parte dessas. A primeira, por sua vez, pode ser considerada na dimensão institucional e do 
processo de ensino e aprendizagem, expressando o acompanhamento da trajetória escolar dos estudantes e da própria escola.

\section{Questão de Pesquisa}

Diante do exposto, entendemos que existem inúmeras questões que dificultam aos professores do ciclo de alfabetização realizar os currículos propostos pelo Governo. Dessa forma, temos um enfrentamento do que Bernstein (1996) chama de discurso pedagógico oficial e discurso pedagógico recontextualizado. Essas discrepâncias, que ocorrem devido a esses entraves, acabam gerando uma distorção entre o currículo proposto e o currículo avaliado, ambos geridos pelo Governo Federal, e o currículo em ação. Logo, essa alteração entre o que é dito pelos gestores, o que é realizado pelo professor e o que é, posteriormente, cobrado pelo Governo, pode nos levar a baixos índices em avaliações externas, fazendo com que o país seja visto com maus olhos pelas entidades que controlam a qualidade de Ensino. Dessa forma, propomos, como questão de pesquisa, compreender como se dá a relação entre essas três "engrenagens" básicas - currículos proposto, em ação e avaliado - para o desenvolvimento da educação brasileira, levando em conta as traduções que são realizadas pelos professores dos discursos pedagógicos oficiais até o campo recontextualizado pedagógico, que é o que de fato acontece na sala de aula.

\section{Objetivo Geral}

Compreender as relações entre os currículos proposto, pelo Governo Federal, o currículo em ação, que é realizado pelo professor em sala de aula, e o currículo avaliado, também pelo Governo Federal por meio das avaliações externas, juntamente com os diferentes discursos que permeiam esses currículos.

\section{Objetivos Específicos}

Dado o objetivo geral, podemos elencar alguns objetivos específicos deste projeto:

- Comparar as habilidades previstas no currículo avaliado, através das avaliações externas com as atividades propostas no currículo apresentado pelos livros didáticos;

- Identificar as concepções dos professores sobre os currículos que são prescritos;

- Analisar as formas pelas quais os professores procuram relacionar o currículo que praticam com os currículos prescritos; 
- Compreender como ocorrem as transformações dos discursos pedagógicos ao longo do desenvolvimento dos currículos.

\section{Metodologia}

O desenvolvimento da pesquisa acontecerá a partir da análise de turmas do segundo ano do Ensino Fundamental de professores parceiros que aceitem participar desse projeto. A escolha pelo segundo ano do Ensino Fundamental se dá em razão de podermos analisar o desenvolvimento da prática do professor, juntamente com as questões desenvolvidas nas avaliações externas, nesse caso, a PBM e a ANA, por serem as avaliações aplicadas no ciclo de alfabetização.

Para o desenvolvimento desta pesquisa optamos por analisar a PBM e a ANA do período compreendido entre 2012 e 2017. Tal escolha se dá por compreender o tempo anterior a última escolha dos livros didáticos no Plano Nacional do Livro Didático - PNLD, que ocorreu em 2015, e o período que essa escolha esteve em vigor. Além disso, poderemos verificar o desenvolvimento da avaliação externa em conjunto com a nova escolha do livro didático pelo PNLD, que ocorre no ano de 2018 para o Ensino Fundamental - anos iniciais. Cabe destacar que optaremos por trabalhar com as três coleções de livros mais escolhidas no País, e que essa limitação ocorre porque compreendemos que, como foram os mais escolhidos, são os que servem de base para o maior número de crianças que realizam a PBM no país. Dessa forma, teremos 12 (doze) PBM, 12 (doze) ANA e seis coleções de livros, inicialmente, para analisar e compreender como acontece a relação entre o currículo avaliado, o currículo proposto e o currículo em ação.

Para Minayo (2001) a pesquisa qualitativa caracteriza-se por abranger questões que não são quantificáveis, tais como: crenças, valores, motivos, percepções, entre outros. Acreditamos ainda, que a pesquisa qualitativa pressupõe que iremos analisar questões subjetivas e inesgotáveis de interpretações. Dessa forma, compreendemos que nossa pesquisa é de caráter qualitativo, pois procuramos analisar como ocorre a relação entre os currículos proposto, em ação e avaliado, através da análise de documentos e das aulas dos professores, com uma visão particular e interpretações próprias do pesquisador. E, ainda, pelo fato de que queremos analisar como a as questões da PBM e da ANA se relacionam com os livros didáticos adotados pelas escolas e com as práticas pedagógicas dos professores, nos colocando diante da realidade e buscando compreender esses dados coletados.

Estabelecemos essa pesquisa numa perspectiva descritiva, pois, para Gil (2002, p.42), "as pesquisa descritivas têm como objetivo primordial a descrição de características de 
determinada população ou fenômenos ou, então o estabelecimento de relações entre variáveis", condizendo com o princípio desse estudo - comparar os currículos proposto e avaliado. Caracterizamos, ainda, essa pesquisa como documental, pois o material a ser analisado é composto pelos livros didáticos trabalhados na maioria das escolas brasileiras, pela PBM e ANA, materiais, estes, que podem receber um tratamento diferente dos que já foram realizados (Gil, 2002), além das anotações realizadas durante as observações realizadas nas aulas dos professores parceiros. Podemos dizer, ainda, que o estudo de caso é outra característica dessa pesquisa, pois iremos coletar dados que estarão na sala de aula junto ao professor daquelas turmas em que iremos nos inserir para compreender os currículos em ação. Para que possamos cumprir com o proposto iremos realizar a análise do conteúdo desses documentos, buscando categorizar e refletir a cerca de cada uma dessas categorias criadas.

\section{Conclusões}

Ainda não se pode tirar conclusões do trabalho aqui descrito, pois este encontra-se em sua fase inicial da analise dos documentos citados e da elaboração de referencial teórico. Espera-se que os sujeitos de pesquisa compreendam as relações entre os currículos oficial, prescrito e avaliado com a sua prática cotidiana. Além disso, procuramos mostrar como os discursos pedagógicos orientados pelo Governo Federal se estruturam e de que forma as releituras que vão sendo feitas ao longo do caminho, até chegarem ao que é realizado na sala de aula por meio das recontextualizações realizadas pelos interlocutores que dele se apropriam, impactam nos indicadores da educação brasileira.

\section{Referências}

BARDIN, Laurence. Análise de conteúdo. Tradução de Luís Antero Reto e Augusto Pinheiro. Lisboa: Edições, 1977.

BERNSTEIN, B. A estruturação do discurso pedagógico: classe, códigos e controle. Petrópolis: Vozes, 1996.

CALDATTO, Marlova Estela. O PROFMAT e a formação do professor de Matemática: Uma análise curricular a partir de uma perspectiva processual e descentralizadora. (Tese de Doutorado em Educação para a Ciência e a Matemática). Universidade Estadual de Maringá: Maringá, 2015.

GIL, Antônio Carlos. Como elaborar um projeto de pesquisa. 4. ed. São Paulo: Atlas, 2002 . 
LIMA, Eliza Maria Baptistella. Um estudo sobre as disciplina de Geometria em cursos de Licenciatura em Matemática. Dissertação. (Mestrado em Ensino de Ciências e Matemática). Universidade Cruzeiro do Sul: São Paulo, 2014.

MARTINS, CliciaBuhrer. Autoavaliação institucional e suas articulações com a reforma curricular de cursos de graduação. Tese. (Doutorado em Educação). Pontifícia Universidade Católica de São Paulo: São Paulo, 2016.

MELCHIOR, Maria Celina. Da avaliação dos saberes à construção de competências. Porto Alegre: Premier, 2003.

MINAYO, Maria Cecília de Souza (org.). Pesquisa Social. Teoria, método e criatividade. 18 ed. Petrópolis: Vozes, 2001.

PALANCH, Wagner Barbosa de Lima. Mapeamento de pesquisas sobre currículos de Matemática na Educação Básica brasileira (1987 a 2012). Tese. (Doutorado em Educação Matemática). Pontifícia Universidade Católica de São Paulo: São Paulo, 2016.

ROLDÃO, Maria do Céu; FERRO, Nuno. O que é avaliar? Reconstrução de práticas e conceções de avaliação. In. Revista Est. Aval. Educ., São Paulo, v. 26, n. 63, p. 570-594. set./dez. 2015.

SACRISTÁN,J. Gimeno; GOMEZ, A. I. Pérez. Compreender e transformar o ensino. Trad. Ernani F. da Fonseca Rosa. 4 ed. Artmed, 1998.

SILVA, Tomaz Tadeu da. Documentos de Identidade: uma introdução às teorias curriculares. 3. ed.; 6. reimp. - Belo Horizonte: Autêntica Editora, 2015.

TEIXEIRA, Dulce Helena Moreira. A história da Avaliação no Estado de São Paulo sob a ótica da legislação: da $1^{a}$ Lei de Diretrizes e Bases (1961) à Progressão Continuada (1998). Dissertação. (Mestrado em Educação) - Centro Universitário Moura Lacerda, Ribeirão Preto. 2007.

WIEBUSCH, Eloisa Maria. Avaliação externa: um caminho para a busca da qualidade da educação. Dissertação de mestrado. PPGEDU/UFRGS. 2011. 